\section{AQUISIÇÃO POR PARTICULARES EM ÁREA PÚBLICA - O CASO DA BARRAGEM POÇO DO MAGRO EM GUANAMBI-BA.}

\section{PUBLIC AREA ACQUISITION BY PRIVATE PERSONS - THE CASE OF POÇO DO MAGRO'S DAM IN GUANAMBI-BA.}

Adaltiva dos Santos Xavier ${ }^{1, *} /$ Edilene Mesquita da Silva Fagundes ${ }^{1}$ / Léia Dias Leal de Souza ${ }^{1}$ / Ravane Neves Reis ${ }^{1}$

\section{INTRODUÇÃO}

O artigo apresenta relevância social por discutir temas relacionados à detenção, posse e propriedade de um empreendimento ligado à sustentabilidade ambiental, desenvolvimento social e econômico em âmbito regional. Dessa forma, serão analisadas os modos de aquisição de área pública por particulares na localidade rural do Poço do Magro, em Guanambi-Ba, cujo zoneamento encontra-se prevista no Plano Diretor Local, sob a égide da Lei $\mathrm{n}^{\circ}$ 223/2007, que dispõe da área de propriedade pública, e avaliará se a extensão do Poço do Magro ocupada por particulares atende à finalidade social previsto na Constituição Federal de 1988, no Código Civil de 2002 e demais legislações correlatas.

Em seguida, será feita uma breve abordagem da origem do açude Poço do Magro e da importância da utilização do solo desse poço nos dias atuais, previsto no artigo 61 do Plano Diretor do município de Guanambi-BA, com o objetivo de observar o uso e a ocupação do solo de acordo a legislação civil vigente no Brasil que discutem detenção, posse e propriedade.

\begin{abstract}
RESUMO
O artigo apresenta relevância social porque discute temas relacionados aos modos de aquisição de um empreendimento ligado à sustentabilidade ambiental, desenvolvimento social e econômico em âmbito regional. Observou-se que a utilização da barragem do Poço do Magro possui várias formas de aquisições, alguns particulares possuem a propriedade, como o poder público, outros, são apenas detentores ou possuidores. Por meio da pesquisa empírica com visita a campo, foi possível verificar também que algumas ocupações estão legalizadas, outras são ilegais, e por isso, tramita junto ao Ministério Público Federal ação civil pública que visa apurar a regularidade dessas aquisições nesta localidade. Dessa forma, objetivou-se analisar, se a extensão do Poço do Magro, objeto de estudo, de fato é área pública ocupada por particulares, e se atende à finalidade social prevista na Constituição Federal de 1988, no Código Civil de 2002 e demais legislações correlatas, vez que a posse e a propriedade devem ser analisadas sob o viés constitucional.
\end{abstract}

Palavras Chave: Aquisição; Direito; Imóvel; Poço do Magro.

\section{ABSTRACT}

The article is socially relevant because it discusses issues related to an enterprise linked to environmental sustainability, social and economic development at the regional level. It was observed that the use of the dam of Poço do Magro has several forms of acquisitions, some individuals own the property, as the public power, others, some private, are only owners or possessors. Through empirical research with field visits, it was also possible to verify that some occupations are legalized, others are illegal, and for this reason, a public civil action is filed with the Federal Public Prosecutor's Office to determine the regularity of these acquisitions in this locality. The purpose of this study was to analyze whether the extension of the dam Poço do Magro, object of study, is in fact a public area occupied by private individuals, and fulfills the social purpose set forth in the Federal Constitution of 1988, the Civil Code of 2002 and other related legislation, since ownership and ownership must be analyzed under constitutional bias.

Keywords: Acquisition; Law; Property; Poço do Magro.

Submetido em: 19 de jun. 2018

Aceito em: 15 de mar. 2019

${ }^{1}$ Faculdade Guanambi - UNIFG. Guanambi, Bahia - Brasil.

*E-mail para correspondência: ada.xfernandes@ gmail.com.

Rev. ComCiência - jun. 2019, vol. 4, no. 4, p. 13-19/ doi: 10.36112/issn2595-1890.v4i1.p13-19 
Também será averiguado a classificação desta área como sendo macrozona especial atendendo à proteção ambiental, o interesse social quanto à sua função, os aspectos econômicos, a preservação do patrimônio histórico, paisagístico e cultural assegurados como garantia fundamental em nosso ordenamento jurídico.

Para melhor compreensão desta temática faz-se necessário o estudo de caso e a pesquisa de revisão bibliográfica por meio do Código Civil brasileiro (2002), Constituição Federal (1988) seguido de doutrinas da área Civil (CARNACCHIONI, 2017; TARTUCE, 2014), Jurisprudências, artigos de revistas científicas especializadas e site de notícias pertinentes ao tema com fins de conceituar os institutos propriedade, posse, detenção, bem como identificar a sua função social. No que se refere ao conceito de Área de Proteção Permanente será utilizado o Código Florestal (2012) e demais legislações que tratam do tema do município de Guanambi-BA.

Numa outra vertente, será necessária a pesquisa empírica com visita a barragem do Poço do Magro para prévio conhecimento do estado em que se encontra o objeto estudado, obtendo diálogos informais com populares, no intuito de aplicar o conhecimento teórico sobre as formas de aquisições atinentes ao direito real sobre as coisas ao caso dos modos de aquisição da barragem Poço do Magro, bem como, observar a eficiência das diretrizes do Plano Diretor proposta no Estatuto da Cidade - Lei 10.257/2011, de maneira a realizar um estudo multidisciplinar.

2. PRINCIPAIS CONCEITOS DE POSSE, PROPRIEDADE E DETENCÃO.
Para melhor compreensão do tema abordado, faz-se necessário diferenciar os conceitos, posse, propriedade e detenção. Para Carnacchioni (2017), a teoria subjetiva clássica da posse foi criada por Savigny, em que o possuidor deve ter dois requisitos:

a. Corpus - que é o contato físico da coisa (CARNACCHIONI, 2017);

b. Animus - Investigar a psique do possuidor, o mesmo deve ter convicção de que é dono da coisa (CARNACCHIONI, 2017).

No entanto, o autor esclarece que a teoria de Savigny sofreu várias críticas, uma vez que a proteção da posse se tornaria muito burocrática, o Juiz precisaria investigar o "animus" caso a caso. Assim, Rudolf Von Ihering criou a teoria objetiva da posse que é adotada pelo código civil de 2002; logo a posse só se dá quando determinada pessoa agir, e se comportar perante o mundo, como dono do bem (CARNACCHIONI, 2017).

Conforme pontua Tartuce (2014), o Código civil de 2002 traz algumas classificações da posse quanto aos seus vícios; que podem ser de natureza objetiva e natureza subjetiva. "É justa a posse que não for violenta, clandestina ou precária". (TARTUCE, 2014). O autor pontua que a posse violenta é aquela adquirida por atos violentos, grave ameaça, violência física, de forma injusta, por isso o sujeito possuidor poderá entrar com uma ação possessória. A posse clandestina é adquirida às ocultas do verdadeiro possuidor, a posse precária, por sua vez, deriva do inadimplemento da obrigação de restituir a coisa; em suma é o abuso de confiança do possuidor que, indevidamente, retém a coisa consigo.

Cabe destacar que para Tartuce (2014), as manifestações da função social da posse se desdobra na usucapião, porém, não se aplica, de acordo com o artigo $183, \S 3^{\circ}$ da Constituição Federal de 1988, aos casos de bens imóveis públicos. Outra forma de manifestação da função social da posse é a aquisição por Acessão, disposto no artigo 1.248 aos 1.252 do código civil de 2002, que geralmente ocorre devido a fenômenos naturais, como por exemplo, a formação de ilhas, (TARTUCE, 2014).

O conceito de detenção está disposto no código civil de 2002 que, para Carnacchioni (2017), possui a mesma linha da teoria objetiva de Ihering com a seguinte definição:

“Art. 1.198. Considera-se detentor
aquele que, achando-se em relação
de dependência para com outro,
conserva a posse em nome deste e
em cumprimento de ordens ou ins-
truções suas.
Parágrafo único. Aquele que come-
çou a comportar-se do modo como
prescreve este artigo, em relação ao
bem e à outra pessoa, presume-se
detentor, até que prove o contrá-
rio”. (BRASIL, 2002).

Nesse aspecto, Savigny apud Carnacchioni (2017), afirma que detentor é aquele que ocupa um bem sem a intenção de um dia vir a se tornar dono deste bem; assim, a diferença entre posse e detenção está alocada no elemento subjetivo da posse "animus", se o possuidor exerce poder de fato sobre a coisa com "animus" de ser dono, está caracterizada a posse, mas se o contato material com a coisa for sem ânimo de dono, o sujeito será mero detentor.

O Código Civil (2002) destaca os poderes inerentes à propriedade, no qual o proprietário tem a faculdade de usar, gozar, dispor da coisa e o direito de sequela de quem quer que, injustamente, a possua ou detenha. Carnacchioni (2017) define a propriedade como um "direito subjetivo comple- 
xo", visto que o proprietário, além de exercer as faculdades jurídicas inerentes ao direito de propriedade, ainda possui inúmeros deveres sociais, que são essenciais para validar e salvaguardar o seu direito. (CARNACCHIONI, 2017).

Torna-se relevante mencionar que para Gomes apud Carnacchioni (2017) os principais atributos da propriedade são a exclusividade, a perpetuidade e a elasticidade, bem como o seu caráter de direito absoluto devido à extensão dos direito do proprietário e a oponibilidade erga omnes, ou seja, atinge a todos.

Feita as distinções sobre as várias formas de se adquirir um bem imóvel, é importante abordar os impactos ambientais, econômicos e sociais que tais obtenções trazem quando ocorre à aquisição de um bem público sem atender as legislações até aqui já mencionados, uma vez que se trata de um terreno que pertence a CODEVASF - Companhia de Desenvolvimento do Vale do Rio São Francisco e do Parnaíba.

\section{DA BARRAGEM POÇO DO MAGRO}

\subsection{Apontamentos históricos}

Em período anterior à construção da Adutora do Algodão que busca a captação e transporte de água do rio São Francisco para as cidades do Sudoeste baiano dentre elas Guanambi, concluída no ano de 2012, existia a Barragem de Ceraíma que proporcionalmente atendia a necessidade da população da cidade na época (CODEVASF, 2005).

No entanto, com a crescente expansão territorial, verificou-se a necessidade da construção de uma barragem maior que viesse a acompanhar esse crescimento populacional.
Por meio dos recursos da União, sob a administração da CODEVASF - Companhia de Desenvolvimento do Vale dos Rios São Francisco e do Parnaíba, no ano de 2005 foi inaugurada a Barragem Poço do Magro, com previsão de abastecimento para os próximos 50 anos. (CODEVASF, 2005).

A Barragem conta com mais de 30 milhões de metros cúbicos de água, beneficiando diretamente mais de 120 mil pessoas da região, segundo relatos da própria Codevasf (2005), sua destinação está voltada à perenização do Rio Poço do Magro para atividades de piscicultura, agricultura familiar e lazer, assegurando o desenvolvimento econômico da região. (CODEVASF, 2005).

\subsection{Das Aquisições de Área Pública por Particulares}

Durante a visita realizada ao Poço do Magro em setembro de 2017, observou-se que a área abriga inúmeros moradores rurais e é potencialmente importante para o desenvolvimento econômico e social da região devido ao ambiente de recursos naturais, artificiais que propicia a agricultura familiar, piscicultura, o lazer, bem como, responde pela perenização, equilíbrio e abastecimento da população adjacente, atendendo aos requisitos da garantia constitucional do direito à propriedade e sua função social (BRASIL, 1988).

O Plano Diretor de Guanambi, no uso de suas atribuições, prevê em seu artigo 59, que o Poder Executivo, por meio de transparência e participação popular, promova o Plano de Desenvolvimento na Macrozona Rural no qual se insere a barragem do Poço do Magro. As diretrizes aqui propostas vão de encontro ao que foi verificado, desde o seu zoneamento socioambien- tal, manejo agroflorestal sustentável, desenvolvimento da piscicultura sustentável, agricultura familiar, e até o desenvolvimento do ecoturismo (GUANAMBI, 2007).

Essa previsão legal, porém, na prática vem tomando outros caminhos, pois percebeu-se que, dentro desta área pública situações adversas às propostas apresentadas, como a posse do entorno da barragem para fins residenciais, condominiais e casas de veraneio com cercas que impedem a entrada da população na adjacência da barragem.

Tornou-se, então, visível o descumprimento da lei municipal 223/07, disposta no art. 60 que veda a implantação de loteamentos para fins urbanos e condomínios fechados em glebas localizadas na macrozona rural, em especial, em ÁREA DE PROTEÇÃO PERMANENTE - APP que está em vias de legalização, exatamente onde se encontram tais edificações.

Com efeito, percebeu-se ao longo da área, desmatamentos, acúmulo de lixo, a posse com demarcações de terrenos com fins de propriedades particulares e falta de acesso para o desenvolvimento da atividade de pesca. Também, o fomento da atividade de agricultura familiar está prejudicado devido à inacessibilidade da barragem, descumprindo, assim, todas as legislações citadas que tratam da posse, propriedade e sua finalidade social, bem como a Lei Municipal no 462/2011, que cria o Parque Ecoturístico Poço do Magro, destinada ao desenvolvimento do ecoturismo com atividades de lazer para a população.

No entanto, a CODEVASF (2005), que é verdadeira proprietária, tem seu direito de reintegração de posse de todas as propriedades adquiridas de forma indevida por particulares, pois, como já mencionado, o código civil veda a propriedade de bens de 
quem injustamente a possua ou detenha e para os casos em que as propriedades na área da barragem estejam legalmente registradas, devem observar o disposto no Art. 1228 Código Civil, $\S 1^{\circ}$ :

$\mathrm{O}$ direito de propriedade deve ser exercido em consonância com as suas finalidades econômicas e sociais e de modo que sejam preservados, de conformidade com o estabelecido em lei especial, a flora, a fauna, as belezas naturais, o equilíbrio ecológico e o patrimônio histórico e artístico, bem como evitada a poluição do ar e das águas. (BRASIL, 2002).

Ademais, observou-se que a utilização da barragem do Poço do Magro possui várias formas de aquisição; alguns particulares possuem a propriedade, bem como o poder público (CODEVASF) e, há aqueles particulares que ocupam bens insuscetíveis de posse previstos no artigo 100, combinado com o artigo 1.228 do código civil de 2002; trata-se de bens públicos, bens de uso comum do povo, por isso não pode ser objeto de posse. A política de desenvolvimento urbano que é executada no âmbito municipal, por meio do Estatuto da Cidade em conjunto com o Plano Diretor, objetiva promover o seu crescimento de modo sustentável, assegurando a função social com vistas a garantir o bem estar dos seus habitantes (BRASIL, 1988).

Desta forma, apesar da garantia constitucional, da legislação civil de proteção e da conservação proposta no plano diretor, principalmente no que tange às áreas especiais, é preciso que a população colabore no sentido de não depredar o patrimônio público na perspectiva de promover o desenvolvimento sustentável para o gozo das presentes e futuras gerações, essencial à sadia qualidade de vida, as- segurada em seu artigo 225, da Constituição Federal de 1988. (BRASIL, 1988).

\section{RESULTADOS E DISCUSSÕES}

De acordo Gil (2002) a pesquisa exploratória objetiva proporcionar maior familiaridade com o problema, com vistas a torná-lo mais explícito ou a constituir hipóteses. Assim no intuito de buscar maior proximidade com o objeto de estudo, realizou-se pesquisas por meio de doutrinas, jurisprudências, e legislações que tratam dos modos de aquisição nos direitos reais, somado a visita a campo com conversas informais com alguns moradores da região, para maior compreensão dos institutos da detenção, posse e propriedade. Os resultados encontrados foram que a posse de bens públicos e a propriedade são os modos mais comuns de aquisição no entorno dessa barragem de Guanambi - Bahia. Verificou-se que existem diversos tipos de ocupações como a construção de casas de veraneio e cercas feitas por particulares no entorno da barragem, que dificulta o acesso das pessoas que utilizam a barragem como forma de subsistência, confirmando a apropriação de áreas públicas por particulares, descumprindo a Constituição Federal de 1988 e o Código Civil de 2002, bem como as legislações municipais de Guanambi - Bahia.

Importante ressaltar que por meio da imprensa local ficou demonstrado que várias pessoas de Guanambi denunciaram tais práticas, e ao procurar alguns representantes dessa imprensa foi informado que há a propositura de uma ação civil pública em face da CODEVASF, pois se observou a omissão do poder público quanto às terras ocupadas por particulares no entorno dessa barragem de forma a não atender a sua finalidade social.

4.1. PROPOSITURA DA AÇÃO CIVIL PÚBLICA EM FACE DA CODEVASF

4.2. Inquérito Civil proposto pelo ministério público federal (em anexo)

Com vistas a averiguar a situação sobre a perspectiva do uso do solo no zoneamento rural da Barragem do Poço do Magro constante do Plano Diretor (Lei 223/2007), realizou-se visita a campo constatando que as ocupações ali registradas, por vezes, estão legalizadas, por vezes, ilegais; cuja apuração estaria sendo realizada pelo Ministério Público Federal.

Assim buscou-se junto ao MPF, tomar vistas aos autos do Processo, pedido esse que fora deferido, qual seja, Inquérito Civil $\mathrm{n}^{\circ}$ 1.14.009.000024/2016-11, que:

Apura a omissão da CODEVASF, em face da Barragem Poço do Magro, tanto pela ausência do levantamento físico da faixa de Área de Proteção Permanente - APP, quanto pela ocupação indevida da área por particulares, inclusive para fins de especulação imobiliária.

Trata-se de uma denúncia feita por um cidadão guanambiense, cujo embasamento se deu a partir da visualização das ocupações indevidas com construções residenciais por particulares, sem finalidade social, no entorno da barragem do Poço do Magro; houve inclusive aterramento da lagoa em determinado marco da barragem, ambos por distintos particulares.

Cabe ressaltar que, dado o $\mathrm{Pa}$ trimônio ambiental, cultural e histórico que permeia a localidade da Barragem Poço do Magro em Guanambi-BA, atendendo ao Código Florestal que 
define Área de Proteção Permanente APP - como:

Área protegida, coberta ou não por vegetação nativa, com a função ambiental de preservar os recursos hídricos, a paisagem, a estabilidade geológica e a biodiversidade, facilitar o fluxo gênico de fauna e flora, proteger o solo e assegurar o bem estar das populações humanas (BRASIL, 2012).

Conforme foi solicitado pelo Ministério Público Federal, em observância à Lei para a criação de uma Área de Proteção Permanente na localidade da Barragem Poço do Magro, a CODEVASF (2005) delimita a Área de Entorno - AE por meio de uma Plano Ambiental de Conservação e Uso do Entorno do Reservatório da Barragem do Poço do Magro - PACUERA, que deve atender alguns requisitos, conforme posicionou-se o Instituto de Meio Ambiente e Recursos Hídricos:

Deve-se realizar o zoneamento do reservatório, identificando os locais para conservação, recuperação ou de acesso às águas do reservatório, e também o corpo hídrico, com proposição de setorização prevendo compatibilização entre qualidade da água, por meio de dados secundários e usos múltiplos desejados. (INEMA, 2016).

O objetivo é efetivar a Área de Proteção Permanente na localidade do Poço do Magro, considerando o meio biótico e abiótico para a sustentabilidade ambiental. Esses documentos estão sendo desenvolvido pela empresa ARCADIS Brasil - Divisão de Meio Ambiente - cujo objetivo é "conciliar os usos previstos da APP (100 metros), como os usos de ocupação da área do entorno do reservatório" (ARCADIS, 2015).

Nesse Cenário, a Prefeitura Municipal de Guanambi buscou reco- nhecer o direito de propriedade dos quilombolas que ali residem e possuem todos os requisitos necessários de proprietários, ou seja, utilizam as terras como meio de subsistência a várias gerações, atendendo aos princípios constitucionais do direito à moradia, bem como a função social da propriedade.

A CODEVASF, por meio de escrituras públicas de compra e venda, no ano de 2004, apresenta nos autos do processo junto ao Ministério Público Federal, documento comprovando a aquisição de alguns terrenos dentro da área em comento, bem como, consta também registros de doações entre pais e filhos, de terrenos nas proximidades do Poço do Magro, datada do ano de 1990, conforme escrituras públicas de doação anexadas ao processo.

Informa ainda que os processos encontram-se em trâmite, com vistas a propor uma Ação de Reintegração de Posse para as propriedades que não estão legalizadas junto ao Registro de Imóveis, encaminhando as certidões de inteiro teor referentes às adquiridas pela CODEVASF, a relação de processos de indenização que compõem a área e os processos administrativos com fins de apurar a invasão na área da barragem (CODEVASF, 2016).

A partir dessas desapropriações, observado o pagamento das indenizações para as propriedades que se encontram legalizadas junto ao Registro de Imóveis na Comarca de Guanambi-BA, a União, sob administração da CODEVASF (2005), torna-se proprietária da área pública demarcada conforme croqui apresentado nos autos pesquisados.

Vale ressaltar que o poder público por meio da União (CODEVASF) afirma tentar resolver esta questão da ocupação indevida por particulares, no entanto a denúncia em análise, proposta pelo Ministério Público Federal, ainda não está conclusa, apontando a omissão da Codevasf, sobre os aspectos dos possuidores, no que tange a esta ocupação irregular.

Conforme consta nos autos do Inquérito Civil, a CODEVASF (20016) formalizou um processo administrativo a partir de Relatório Técnico de Inspeção feito pelo Escritório de Apoio Técnico de Guanambi em 23/06/2015 (vinte e três de junho de dois mil e quinze) e, em atenção à denúncia registrada pela sua Ouvidoria, com o intuito de juntar documentos necessários para propositura de uma Ação de Reintegração de Posse.

Essa medida judicial é cabível nos casos de esbulho, definido por Carnacchioni (2017) como a perda da posse, seja ela total ou parcial. A reintegração visa afastar a indevida invasão da propriedade e a recuperação da coisa perdida pelo legítimo possuidor. No caso de posse irregular de área pública, ainda que seja comprovada a omissão da empresa pública responsável, no caso, a CODEVASF, o possuidor irregular não terá direito a nenhum tipo de reparação, assim é o entendimento jurisprudencial. Vejamos: Apelação reintegração de posse
área pública ocupante irregular ca-
bimento. Mantença. Ocupante que
não detém título jurídico conferido
individualmente pela Administra-
ção, por ato ou contrato, mediante
autorização legal ou regulamentar,
ou através de consentimento pela
autoridade competente (autoriza-
ção, permissão, cessão, concessão).
A negligência do agente público
não gera direito de reparação ao
ocupante irregular. A mera deten-
ção, em face da sua precariedade
não gera direitos de posse e tam-
pouco a retenção ou indenização de
benfeitorias. Decisão mantida. Re- 
curso negado. (TJ-SP - Apelação: $232327020118260482 \quad$ SP 0023232-70.2011.8.26.0482, Relator: Danilo Panizza, Data de Julgamento: 27/11/2012, 1ª Câmara de Direito Público, Data de Publicação: 27/11/2012).

Nesse sentido, constatado a ocupação irregular de área pública no entorno da Barragem do Poço do Magro, a empresa pública responsável poderá propor uma Ação de Reintegração de Posse em desfavor do possuidor irregular, na qual a CODEVASF deverá provar a sua titularidade. Sendo assim, o pressuposto para não cabimento de indenização pelas benfeitorias edificadas no imóvel pelo ocupante é a inexistência de posse, seja de boa-fé ou má-fé, previstos nos artigos 1.219 e 1.220 do Código Civil. (BRASIL, 2002).

\section{CONSIDERAÇÕES FINAIS}

Diante dos fatos apresentados, é notório que a ocupação do solo no entorno da Barragem Poço do Magro ainda carece de uma resolução. Conforme indícios levantados pela própria empresa pública responsável pela barragem, a CODEVASF, assim como denúncias registradas na Ouvidoria desta, há ocupações irregulares que precisam ser apuradas. O Ministério Público Federal, através do Inquérito Civil em andamento, que apura a omissão da referida empresa pública, busca identificar desídia quanto ao cumprimento das normas regulamentadoras, tal qual o seu papel como proprietária; onde exige-se que seja dada àquelas propriedades a sua função social.

Constatou-se que a Barragem do Poço do Magro é de suma importância para o município, seja para os moradores que ali residem e sobrevi- vem do poço, seja para o desenvolvimento econômico do município de Guanambi, uma vez que, sendo atendido o que preconiza o seu Plano Diretor em consonância com o Estatuto da Cidade, é notório que o ganho em relação às funções sociais e econômicas impulsionariam o desenvolvimento da região e o bem-estar população dado ao grande potencial geográfico.

No entanto, o que se percebe nos levantamentos de dados da visita a campo e no Inquérito Civil Instaurado, é que a referida barragem, na atualidade, beneficia um número restrito de pessoas, que fazem uso da mesma em detrimento da coletividade, notoriamente contrariando a proposta da macrozona especial rural no que tange aos objetivos sociais e econômicos, e a função social da propriedade. Assim, nos conformes do entendimento jurisprudencial, necessário se faz da desapropriação pela posse, em favor da população, de modo a efetivar o lazer, a economia, a função social nesta propriedade, compatibilizando com o equilíbrio ecológico.

A guisa de conclusão esperase que com esta breve análise, a autoridade competente junto com a população conheça os problemas elencados quanto aos modos de aquisição da barragem poço do Magro, e alcance no âmbito da legalidade lograr êxito com relação à destinação desta propriedade, conferindo à coletividade o que se expressa no plano diretor local, como forma de assegurar e garantir o direito fundamental à propriedade prevista no código civil brasileiro e na Constituição Federal Brasileira.

\section{REFERÊNCIAS}

BRASIL. Lei $n^{\circ} 462$ de 20 de Abril de 2011. Dispõe sobre a criação do Parque Ecoturístico Poço do Magro. Publicado no Diário Oficial do Município de Guanambi-Bahia. Ano III, nº 036, 2011.

BRASIL. Ministério Público Federal: apura a omissão da CODEVASF, em face da Barragem Poço do Magro, tanto pela ausência do levantamento físico da faixa de Área de Proteção Permanente - APP, quanto pela ocupação indevida da área por particulares, inclusive para fins de especulação imobiliária. Inquérito Civil $n^{\circ}$. 1.14.009.000024/2016-11. Guanambi, 2016. 1 CD ROM.

BRASIL. Arcadis. Plano Ambiental de Conservação e Uso do Entorno do Reservatório Artificial da Barragem do Poço do Magro - PACUERA. Disponível em

<http//www.arcadis.com/pt/brasil.> Acesso em 02/11/2017.

BRASIL. Tribunal de Justiça do Estado de São Paulo. Apelação $\mathrm{n}^{\circ}$ 231327020118260482 SP 002323270.2011.8.26.0482. Recorrente: Gerson Martins Soares. Recorrida: Prefeitura Municipal de Álvares Machado. Relator: Danilo Panizza. Data do Julgamento: 27/11/2012, $1^{\mathrm{a}}$ Câmara de Direito Público. Data de Publicação: 27/11/2012. Disponível em: http://www.tjsp.jus,br. Acesso em 02 de nov. de 2017.

BRASIL. VADE MECUM SARAIVA. $21^{\mathrm{a}}$ ed. atual. e ampl. São Paulo: Saraiva, 2016. 
com Ciêncio

Uma revista multidisciplinar
CARNACCHIONI, Daniel. Manual de direito civil: volume único. Salvador: JusPodivm, 2017.

FILHO, M.; Rêgo, C.E. Revista Brasileira de Direito Civil. Volume 2. Out/Dez 2014. Disponível em $<$ http//ibdcivil.org.br>. Acesso em 03/11/2017.

Gil, Antônio Carlos, 1946- Como elaborar projetos de pesquisa/Antônio Carlos Gil. - 4. ed. - São Paulo : Atlas, 2002

JHERING, Rudolf Von. Teoria Simplificada da Posse. Tradução: Ricardo Rodrigues Gama. $1^{\text {a }}$ ed. Campinas: Russel Editores, 2005.

JORNADAS DE DIREITO CIVIL I, III, IV e V: enunciados aprovados/coordenador científico Ministro Ruy Rosado de Aguiar Junior. - Brasília: Conselho de Justiça Federal, Centro de Estudos Judiciários, 2012.

QUILOMBO. Site de notícias rede acontece. Assistência Social articula trabalho para reconhecimento da Comunidade Morro de Dentro como Remanescente. Disponível em: < http://www.guanambi.ba.gov.br/notici as/assistencia_social_articula_trabalho _para_reconhecimento_da_comunidad e_de_morro_de_dentro_como_remane scente_de_quilombo-798>. Acesso em 02/11/2017..

\section{SITE DO MINISTÉRIO PÚBLICO} FEDERAL. MPF apura omissão da Codevasf em relação à ocupação irregular na barragem de Poço do Magro, em Guanambi (BA). Disponível em $<$ http//www.mpf.mp.br>. Acesso em: 04 de nov de 2017.
TARTUCE, Flávio. Direito civil, v. 4: direito das coisas. - 6. ed. rev., atual. e ampl. - Rio de Janeiro: Forense; São Paulo: MÉTODO, 2014. 